\title{
Contingent visual marking by transients
}

\author{
MATTHEW S. PETERSON, ARTEM V. BELOPOLSKY, and ARTHUR F. KRAMER \\ University of Illinois at Urbana-Champaign, Urbana, Illinois
}

\begin{abstract}
Preview search is a phenomenon in which a set of new items can be searched with seemingly no interference from items already present in the display. The preview effect has been shown to occur only when the presentation of the new items is accompanied by a luminance change (Donk \& Theeuwes, 2001). In a series of experiments, we extend the type of transients that can lead to a preview benefit to offsets and motion, and confirm Donk and Theeuwes's finding that equiluminant color changes do not lead to a preview effect. Like Donk and Theeuwes, we find that preview search does not occur when only the old items undergo a transient change, suggesting that the processes responsible for preview search are triggered when the new items undergo a change detectable by the magnocellular system. In addition, we find that irrelevant transients interfere with preview search only when they match the current attentional set (e.g., luminance change or motion). Results suggest that preview search is not the automatic capture of attention by transients, but rather is contingent on top-down control settings.
\end{abstract}

Visual marking is phenomenon in which a group of new items can be searched with seemingly no interference from other items in the display. In a typical visual marking experiment, a preview search paradigm is employed in which a group of stimuli is presented followed roughly $1 \mathrm{sec}$ later (the gap interval) by a second group of stimuli that can contain the target (Watson \& Humphreys, 1997). The new set of stimuli intermingles with the old set in such a way that simple spatial strategies (e.g., attending to all of the objects in the upper right-hand portion of the display) cannot be used to segregate the stimuli. In the preview condition, search times are independent of the number of old items in the display and dependent on the number of new items, suggesting that only the new items are attended. Up to 30 new and old items can appear in the display with no degradation in the preview benefit (Theeuwes, Kramer, \& Atchley, 1998).

According to Watson and Humphreys's $(1997,1999)$ visual marking account, the preview benefit occurs through the top-down inhibition of old objects. The gap period between the presentation of the old and the new items is needed to allow observers sufficient time to build up inhibition at the locations of old objects; when the gap interval is too short (less than $400 \mathrm{msec}$ ), there is insufficient time for inhibition to build up at the locations of the old items and marking does not occur (however, see the General Discussion for an alternative interpretation). Even

This research was supported by a grant from the National Institute on Aging (AG14966) and a cooperative research agreement from the Army Research Laboratory (DAAL01-96-2-0003). We thank Shawn Bolin and Jennifer Peterson for their assistance in running participants. Correspondence should be addressed to M. Peterson, Department of Psychology, George Mason University, MS 3f5, 4400 University Dr., Fairfax, VA 22030 (e-mail: mpeters2@gmu.edu), or A. Belopolsky, Beckman Institute, University of Illinois, 405 N. Mathews, Urbana, IL 61801 (e-mail: belopols@uiuc.edu). when there is sufficient time for visual marking to occur, changes to the structure or luminance of the old items will abolish marking.

More recently, Donk and Theeuwes (2001) have suggested that the preview benefit is triggered by the sudden onset of the new stimuli. When the new items are equiluminant with the background, there is no preview benefit; when the new items occur as onsets, the number of old items has no effect on search performance. In contrast to the luminance of the new items, the relative luminance of the old items has no effect on the preview benefit. These results suggest that the preview benefit is dependent on the new items undergoing a change detectable by the magnocellular system.

An alternative view is that the preview benefit occurs because of the temporal asynchrony between the old distractor and new search items (Jiang, Chun, \& Marks, 2002a, $2002 b$ ). That is, the temporal asynchrony allows observers to segregate the items into old and new sets. Changes that interfere with the asynchrony of the presentation of the old and new items disrupts the temporal segregation process. However, the temporal asynchrony hypothesis cannot explain the results of Donk and Theeuwes (2001), in which there is temporal asynchrony between the presentation of both sets of items, yet no preview effect occurs when the new items are equiluminant with the background.

The finding that the preview benefit is dependent on whether or not the new items occur as onset transients is detrimental to Watson and Humphreys's (1997) visual marking account, which attributes the preview benefit to the active suppression of the old items before the new items appear. Although Watson and Humphreys (1998) have suggested that by inhibiting distractor items, marking enhances sensitivity to a luminance change, this does not explain why marking does not occur when the new search items appear through an equiluminant color change. That is, according to the visual marking account, the preview 
effect occurs because the old items are inhibited during the gap period, and this inhibition carries over to the search task, preventing the old distractor items from being processed and interfering with search. By this logic, the preview benefit should still occur when the new items appear via an equiluminant color change.

Previously, Watson and Humphreys (1997) found that making a luminance change to the old items at the same time the new items onset abolished the preview benefit (Experiments 4 and 5). They suggested that the reason the luminance change to the old items abolished the preview benefit was because it interrupted the inhibitory tagging of the old items. An alternative account would be to suppose that adding additional transients to the display (luminance increments or decrements of the old items) made the onsets more difficult to detect. This is in line with Martin-Emerson and Kramer (1997; see also Miller, 1989), who have shown that onsets are less likely to capture attention as more offset stimuli are added to a display.

If the preview benefit is dependent on a visual transient occurring at the location of the new items, then it is possible that a preview benefit might occur for other types of visual transients. The findings of Donk and Theeuwes (2001) suggest that these other types of transients must stimulate the magnocellular system. The magnocellular system is sensitive to motion and rapid luminance changes, whereas the parvocellular system is sensitive to hue and fine spatial frequencies. When the new stimuli were defined by equiluminant color transients, which would be detectable only by the parvocellular system (Lehky, 2000; Livingstone \& Hubel, 1987, 1988), Donk and Theeuwes's participants failed to exhibit a preview benefit. In the first section of this paper, we investigate whether other transients that are detectable by the magnocellular system can lead to a preview benefit. In the second part of this paper, we investigate whether the preview benefit can be limited to only certain classes of transients based on attentional control settings (Folk, Remington, \& Johnston, 1992, 1993; Folk, Remington, \& Wright, 1994). More specifically, the second part of this paper examines whether observers can limit their selection to a specific type of transient while ignoring irrelevant transients that have otherwise been shown to lead to a preview benefit.

\section{Overview of This Article}

In the following series of experiments, we examined the role that magnocellular transients and attentional control settings play in producing the preview benefit. Throughout this paper, we will define the search subset not on the basis of the order of presentation, but rather on the basis of instructions for the task at hand, thus making a distinction between the subsets of the search and the distractor items. This allows us to specify which items are relevant to the task at hand without confusing their order of presentation. In the traditional preview task, the old previewed items were the distractors, and the new items were members of the search set. In addition, we will refer to the pattern of data in which distractor items have no effect on how efficiently the search set is examined as the preview benefit. Mechanisms that are hypothesized to lead to the preview benefit, such as Watson and Humphreys's (1997) visual marking account or Donk and Theeuwes's (2001) capture hypothesis will be referred to specifically.

In the first group of experiments (Visual Marking of Transient Stimuli), we found that onsets, offsets, and motion transients can all lead to a preview benefit. In Experiment 1 , we found that a preview benefit occurs for search items that are defined by onset or offset transients, but not for search items that are defined by an equiluminant color change. Experiment 2 demonstrates that a preview benefit can occur for search items defined by synchronous motion (common fate), and Experiment 3 demonstrates that this is not due to simple image segregation. The experiments reported in the second section, Contingent Visual Marking, investigated whether the preview benefit is contingent on top-down attentional control settings. In those experiments we found that there is no preview benefit when a secondary transient occurring subsequent to the preview transient (but before the search stimuli are revealed) is from the same class as the preview transient. For the purpose of this article, we will be looking at two classes of changes that can be detected by the magnocellular system: luminance change (onsets and offsets) and motion.

\section{VISUAL MARKING OF TRANSIENT STIMULI}

\section{Experiments 1A-1C: Marking by Luminance Transients}

Donk and Theeuwes (2001) found that the preview benefit occurred only when the search stimuli were defined by onsets; when the search items were defined by an equiluminant color change, participants were unable to mark. This suggests that other magnocellular transients, such as offsets, might also lead to a preview benefit. In Experiment 1C, we investigated whether a preview benefit would occur when offset transients defined the search items. Experiments $1 \mathrm{~A}$ and $1 \mathrm{~B}$ were replications of Donk and Theeuwes, demonstrating that a preview benefit can occur for onsets (1A) but not when the stimuli are defined by an equiluminant color change (1B).

\section{Method}

Participants. Twenty-four students (8 males and 16 females) from the University of Illinois were paid to participate. The average age of the participants was 20 years. In all experiments discussed in this paper, all participants had normal or corrected-to-normal visual acuity and normal color vision as measured by the Ishihara color vision test (Ishihara, 1989). The participants were assigned to one of three groups, with each group participating in the onset, offset, or equiluminant condition.

Apparatus. An Apple Power Macintosh 7100/66 running custom software was used to present the stimuli, control the timing of the experimental events, and record participants' response times (RTs) RTs were accurate to $2 \mathrm{msec}$. Stimuli were displayed using a 14-in. Apple Color Display.

Stimuli. The stimuli consisted of letters approximately $0.18^{\circ}$ in width and $0.37^{\circ}$ in height. The distractors were the letters of the alphabet excluding I, N, Q, S, T, Y, and Z, and the target was a Z or a 

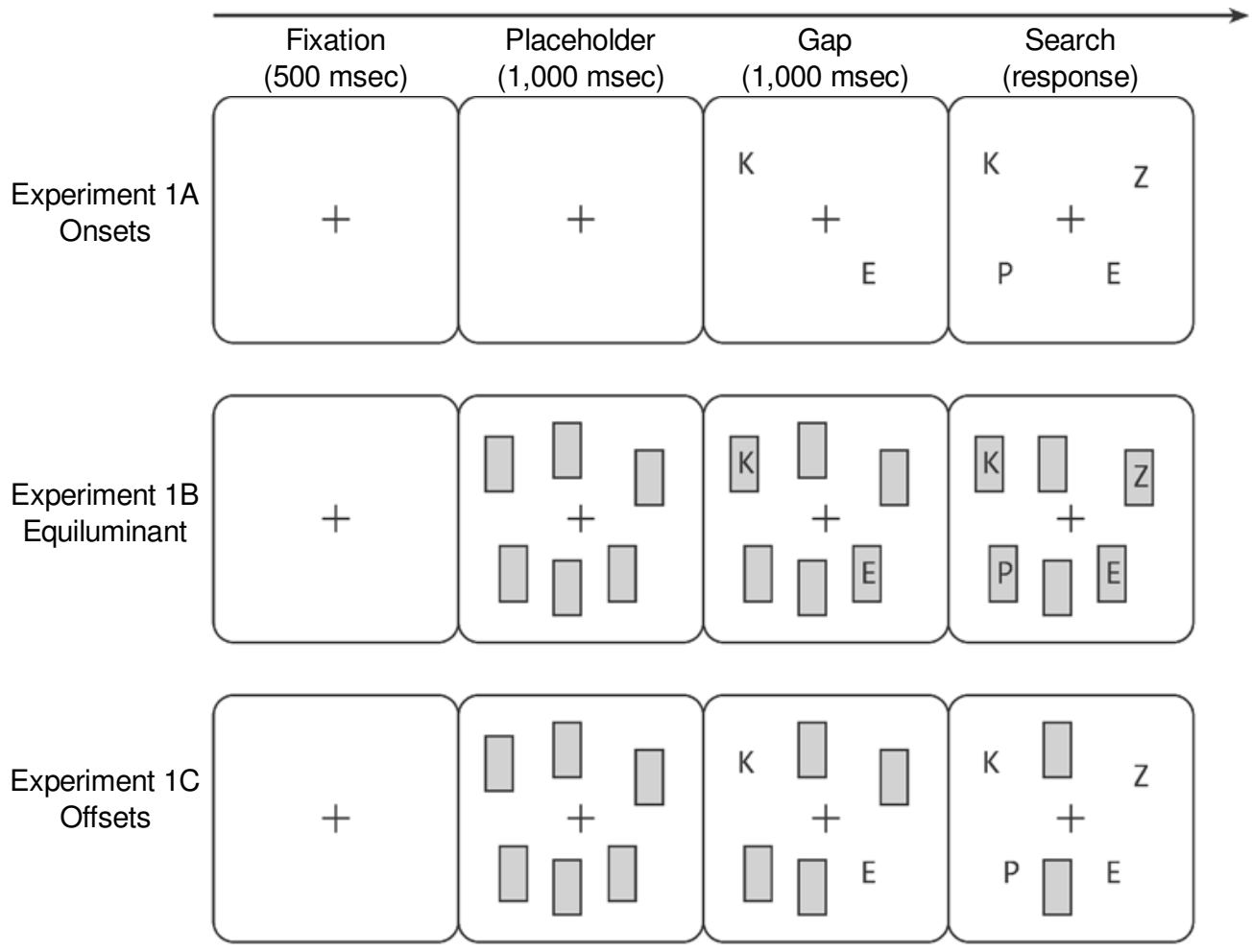

Figure 1. Examples of the onset, equiluminant, and offset displays of Experiment 1. In the example, only two distractor and two search items are present; in the actual experiment, the number of distractor and search items ranged from three to nine items. Placeholders are shown in gray. In the onset display (top row), the distractor items appeared as onsets (third row) and the search items joined them 1,000 msec later (rightmost panel). In the equiluminant conditions (middle row), the display initially contained placeholders marking the possible future positions of the distractor and search items (second from left). Note that in the equiluminant and offset conditions, there were more placeholders than stimuli. Distractor and search items were displayed by being painted on top of the equiluminant placeholders. The offset displays (bottom row) were identical to those in the equiluminant displays except that the distractor and search items were revealed by offsetting the placeholders and replacing them with the green stimuli.

reverse $\mathrm{Z}$ (Figure 1). For the equiluminant and offset conditions, placeholders consisted of filled gray rectangles approximately $0.23^{\circ}$ in width and $0.41^{\circ}$ in height. The letters appeared in green and the background was black. The luminances of the colors were matched for each participant using a heterochromatic flicker fusion test (Ives, 1912) to the gray standard used for the placeholders (mean luminances of 5.6 and $4.7 \mathrm{~cd} / \mathrm{m}^{2}$ for green and gray, respectively). The stimuli could occur in any of 36 positions laid out in a $6 \times 6$ matrix. Participants viewed the screen from a distance of approximately $60 \mathrm{~cm}$.

Design. All experiments in this paper featured a design similar to that used by Theeuwes et al. (1988), in which the number of distractor and search items is orthogonally manipulated. This allows us to directly test whether or not the distractor or search items affected search times without resorting to the indirect measure of search slope ratios. In addition, each experiment contained blocks of trials in which the preview transient was either present (experimental condition) or absent (baseline condition). These are functionally equivalent to the gap (preview) and conjunction conditions used by Watson and Humphreys (1997).

In Experiments 1A-C, gap presence (gap or no-gap), the number of distractor items $(3,6$, or 9), and the number of search items $(3,6$, or 9) were manipulated orthogonally as within-subjects variables. Gap and no-gap conditions occurred in separate blocks of 20 trials, and their order was counterbalanced across participants. There were 20 trials per condition, for a total of 360 trials.
Procedure. Examples of the temporal order of events are shown in Figure 1. Participants started each trial by viewing a fixation cross for $500 \mathrm{msec}$. The fixation cross was followed by a placeholder screen that lasted for 1,000 msec. On gap trials, the placeholder screen was followed for 1,000 msec by the gap display. The final stimulus display was shown until the participant responded with a keypress.

The placeholder display contained the gray stimulus placeholders for the equiluminant (1B) and offset (1C) experiments. Placeholders occurred in all 36 possible stimulus locations and there were more placeholders than stimuli. This prevented participants from using the remaining placeholders as cues as to the exact locations where the search items would appear. For the onset experiment, only a fixation cross appeared. For the gap trials, the distractor items first made their appearance during the gap display and stayed on throughout the rest of the trial; in the no-gap trials the placeholder display was followed immediately by the response display. Response display always contained all of the search items. That is, for the gap condition, the response display was the first display to contain the search items, and for the no-gap condition, it was the first display to contain any search items.

For the offset experiment (1C), items were presented by removing the placeholders and replacing them with stimuli. For the equiluminant experiment (1B), the search items were presented on top of their existing placeholders. For the onset experiment (1A), the search items were presented without placeholders. 
Participants were instructed whether a block of trials was a gap or no-gap block. For the gap blocks, participants were told that they should search the second group of items for the target and to ignore the first group.

Participants responded by pressing the " $\mathrm{z}$ " key if a target $\mathrm{Z}$ was present and the "/" key if a reverse $Z$ was present. Participants served in a single 30-min session consisting of 15 practice trials and 360 experimental trials.

\section{Results}

Error rates. Error rates for the three experiments were analyzed with three-way repeated measures analyses of variance (ANOVAs), with distractor set size $(3,6$, or 9), search set size $(3,6$, or 9), and trial type (conjunction or gap) as within-subjects variables. None of the main effects or interactions reached significance $(p s>.1)$. The overall error rate was $2.1 \%$.

Response times. For all experiments presented in this paper, any RT twice each participant's cell's mean was excluded from analysis. In addition, RTs for incorrect responses were not analyzed.

RTs for the gap and no-gap conditions relative to the number of distractor and search items can be seen in Figure 2. RTs for each experiment were analyzed using threeway repeated measures ANOVAs, with trial type (gap
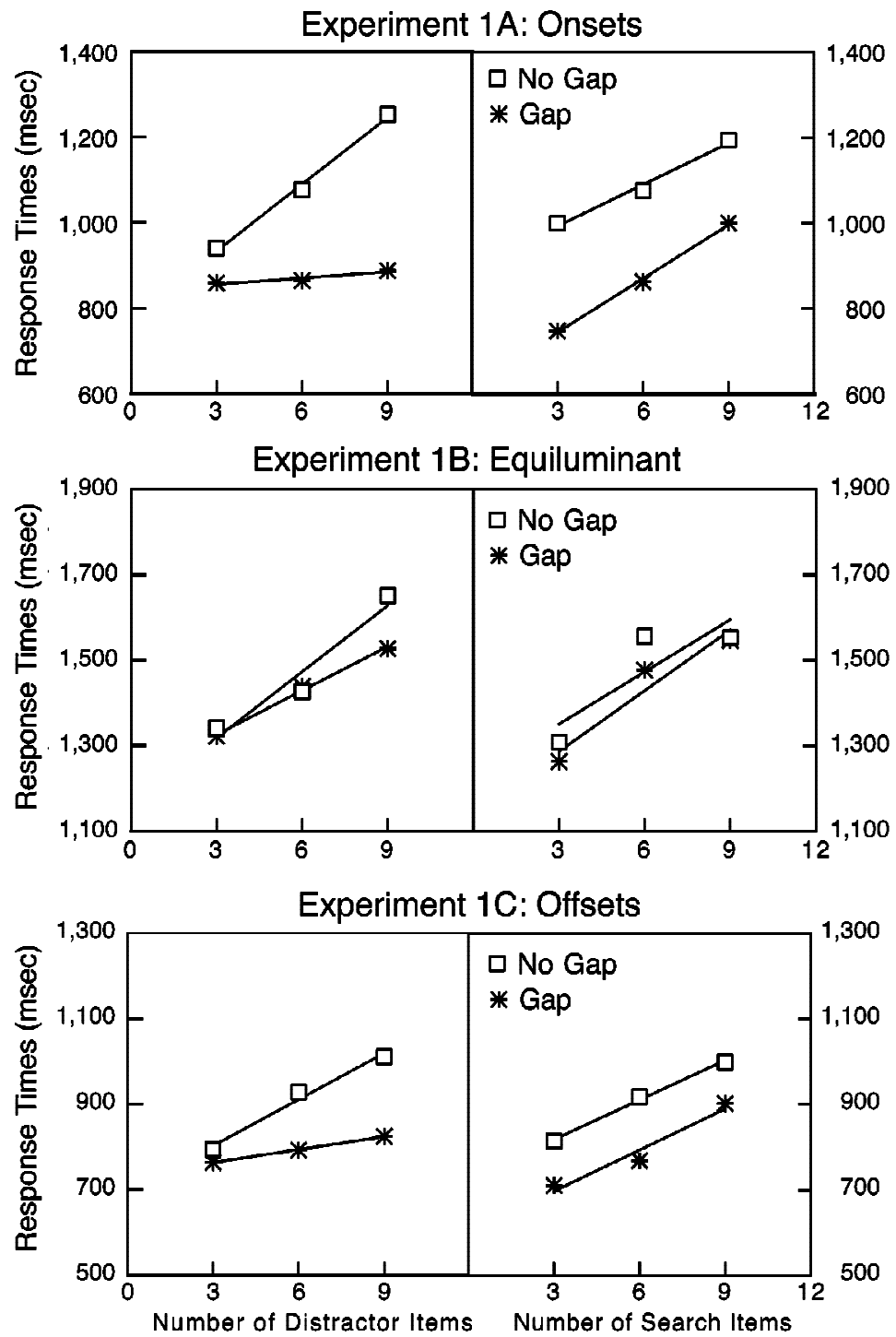

Figure 2. RTs for Experiments 1A-1C. The left-hand panels show the effect of the gap and no-gap conditions relative to the number of distractor items, and the right-hand panels display the gap and no-gap conditions relative to the number of search items. In the onset and offset experiments, the distractors had no effect on search in the gap conditions. However, the distractors did affect search in the gap condition of the equiluminant experiment, and observers were therefore unable to visually mark. 
present or absent), the number of distractor items $(3,6$, or 9 ), and the number of search items $(3,6$, or 9) as independent variables. For Experiment 1A (onsets), we found that the number of search and the number of distractor items affected RTs $[F(2,14)=59.1$ and $15.3, p$ s $<.01$, for the number of search and distractoritems, respectively], and as can be seen in Figure 2, gap trials were responded to more quickly than no-gap trials $[F(1,7)=7.5, p<.05]$.

Of more importance are the interactions between gap presence and the number of search and distractor items. The signature of the preview benefit is that the distractor items have a smaller effect on search times than they do in instances in which the preview effect cannot occur. That is, when the preview effect occurs, the number of distractor items and gap presence (or experiment vs. baseline, in later experiments) should interact. Likewise, the search items should affect RT equivalently in both gap and nogap conditions, meaning that the number of search items and display type should not interact.

As can be seen in the top panel of Figure 2, the number of distractor items had a smaller affect on RT during the gap condition relative to the no-gap condition, as demonstrated by the interaction between the number of distractor items and the type of display $[F(2,14)=15.0, p<$ $.01]$. The number of search items and the type of display failed to interact $[F(2,14)=1.4, p>.10]$, meaning that the number of search items affected RTs equivalently in both conditions. More specifically, these results indicate that observers were able to successfully mark when the search items were defined by an onset. No other main effects or interactions reached significance.

As in Experiment 1A (onsets), both the number of search and the number of distractor items affected search times in Experiment $1 \mathrm{~B}$ (equiluminant) $[F(2,14)=14.7$ and $16.6, p \mathrm{~s}<.01$, for the number of search and distractor items, respectively]. However, gap presence had no effect on search times $[F(1,7)<0]$. More importantly, gap presence and the number of distractor items failed to interact $[F(1,14)=1]$, indicating that participants were unable to visually mark when the items were defined by equiluminant color changes. No other main effects or interactions reached significance.

The results of Experiment 1C (offsets) are identical to the pattern of results for Experiment $1 \mathrm{~A}$ (onsets). The number of search and distractor items both affected RTs $[F(2,14)=28.5$ and $26.4, p s<.01$, for the number of search and distractor items, respectively], and trials were responded to sooner when a gap was present $[F(1,7)=12.9$, $p<.01]$. Critically, gap presence and the number of distractor items interacted $[F(2,14)=10.6, p<.01]$, with distractor items having little effect in the gap trials, indicating that participants were able to visually mark when the search items were defined by offsets. No other main effects or interactions reached significance.

\section{Discussion}

Experiment 1 demonstrates that offset transients can also lead to a preview benefit. In addition, there was no pre- view benefit when the search items were defined by an equiluminant color change, replicating the results of Donk and Theeuwes (2001). ${ }^{1}$ The results support our proposal that magnocellular transients are necessary for a preview benefit. In addition, our replication of Donk and Theeuwes's finding that the preview effect is critically dependent on the nature of the transient marking the location of the search items is at odds with Watson and Humphreys's (1997) hypothesis that visual marking is dependent on the inhibition of older items before the newer items appear. This issue will be discussed further in Contingent Visual Marking, below.

\section{Experiment 2: Marking by Motion Transients}

In line with our proposal that the preview benefit occurs through stimulation of the magnocellularpathway, Experiment 2 tested whether the preview effect can occur when the search stimuli are defined by motion. Like Experiments $1 \mathrm{~B}$ and 1C, Experiment 2 featured a set of placeholders to mark the future locations where the stimuli would be revealed. However, in Experiment 2 the future locations of the search stimuli were indicated by briefly swirling a subgroup of placeholders. The placeholders then remained static and a short time later were removed to reveal both the search and distractor stimuli. This is fundamentally different from previous preview search experiments, in which the marking transient (onset or offset) occurred simultaneously with the revelation of the search stimuli. That is, to successfully perform the task in Experiment 2, observers had to be able to encode which placeholders contained the marking transient (motion in this case) and remember these items while waiting for the stimuli to be revealed.

Although the role of motion is not new to the visual search literature, previous investigations have concentrated on the role that motion plays either during conventional visual search tasks (McLeod, Driver, \& Crisp, 1988; McLeod, Driver, Dienes, \& Crisp, 1991; Royden, Wolfe, \& Klempen, 2001; Verghese \& Pelli, 1992; Watson \& Humphreys, 1999) or during the gap period of otherwise conventional onset-defined preview search tasks (Watson, 2001; Watson \& Humphreys, 1998). In contrast, Experiment 2 investigated whether motion can be the target group defining feature for preview search.

\section{Method}

Participants. Twelve students ( 8 males and 4 females) from the University of Illinois were paid to serve in the study. The average age of the participants was 24.5 years.

Design. In Experiment 2, trial type (static or movement), the number of distractor items (3, 6, or 9), and the number of search items $(3,6$, or 9) were manipulated orthogonally as within-subjects variables. Static and movement conditions occurred in separate blocks of 20 trials, and their order was counterbalanced across participants. There were 20 trials per condition, for a total of 360 trials.

Stimuli. The stimuli consisted of triangles and circles approximately $0.46^{\circ}$ in diameter drawn on a black background (Figure 3). Each stimulus contained either a left- or right-leaning diagonal line. Placeholders were formed by overlapping all possible stimulus con- 


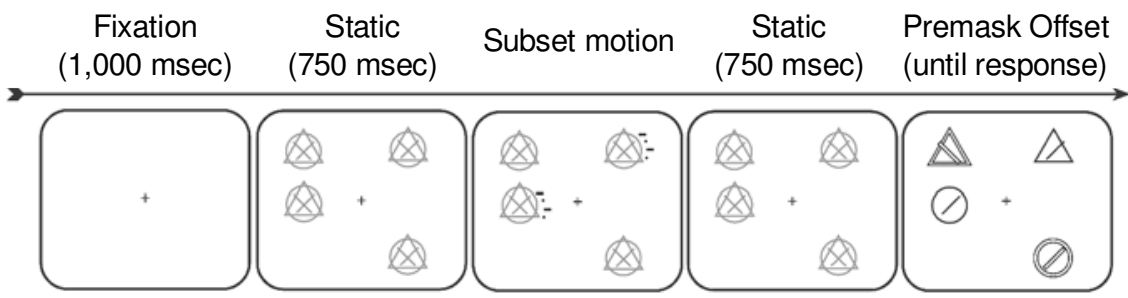

Figure 3. Time course and stimuli for the motion condition of Experiment 2. Participants initially viewed a fixation cross, followed by the presentation of the placeholders. After $750 \mathrm{msec}$, a subset of placeholders swirled in synchrony for $135 \mathrm{msec}$, followed by a 750 -msec static placeholder display. The premask placeholders then offset, revealing the stimuli. In the static condition, the placeholders remained static throughout the trial.

tours. The stimuli appeared in red or green, with each group of stimuli (distractor or search) restricted to a single color. Placeholders were gray. For each participant, the target was defined as a specific conjunction of color and shape (e.g., green triangle), and each combination of color was counterbalanced across participants. That is, the distractors would appear in green and the search items in red, or vice versa. A target was present on every trial, and the participants' task was to determine whether the target contained a left- or rightleaning line. Motion was created by displacing the placeholders 1 pixel $\left(0.023^{\circ}\right.$ of visual angle $)$ in a counterclockwise direction every $15 \mathrm{msec}$ (one screen refresh). That is, motion was created by having each search item placeholder trace a counterclockwise path around its own axis. The items remained upright during the motion and did not change their orientation.

Procedure. The timecourse of events can be seen in Figure 3. Each participant began a trial by viewing a fixation cross for $500 \mathrm{msec}$. The fixation display was then replaced by the placeholder display, which lasted for a total of $1,635 \mathrm{msec}$. In the static condition, the placeholders remained stationary for the entire period of time. In the motion condition, after the first $750 \mathrm{msec}$, the placeholders marking the search items synchronously swirled counterclockwise for $135 \mathrm{msec}$, followed by another $750 \mathrm{msec}$ of static placeholders. Items were swirled by displacing them 1 pixel every screen refresh; swirling did not alter the items' orientation. After the placeholder display had ended, the response display came on, revealing all of the stimuli. Participants were told to attend to the items that briefly moved and to ignore the static items.

\section{Results}

Error rates. Error rates were analyzed using a threeway repeated measures ANOVA with trial type (static or movement), the number of distractor items $(3,6$, or 9$)$, and the number of search items $(3,6$, or 9$)$ as independent variables. None of the main effects or interactions reached significance. The overall error rate was $2.6 \%$.

Response times. RTs for the static and movement conditions relative to the number of distractor and search items can be seen in Figure 4. RTs were analyzed using a three-way repeated measures ANOVA, with trial type (static or movement), the number of distractor items $(3,6$, or 9 ), and the number of search items $(3,6$, or 9$)$ as independent variables. Both the number of search items and the number of distractor items affected RTs $[F(2,22)=40.5$

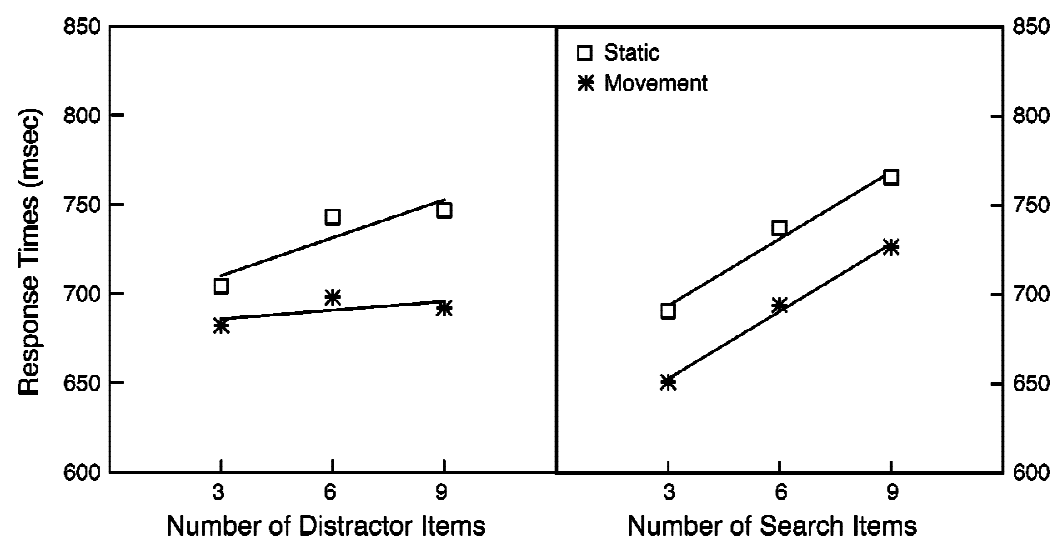

Figure 4. Response times for Experiment 2. The left-hand panel shows the effect of the static and movement conditions relative to the number of distractor items, and the right-hand panel displays the static and movement conditions relative to the number of search items. As can be seen in the left-hand panel, the distractor items had a smaller effect in the movement relative to the static condition, indicating that participants were able to visually mark when the search stimuli were defined by motion. As shown in the right-hand panel, search items had an equivalent effect in both conditions. 
and $14.0, p \mathrm{~s}<.05$, for the number of search and distractor items, respectively]. In addition, RTs were faster in the movement condition $[F(1,11)=14.2, p<.05]$.

Of more importance are the interactions between the presence of motion (analogous to the gap and no-gap conditions in other experiments in this paper) and the number of search and distractor items. The signature of the preview effect is that the distractor items have a smaller effect on search times than they do in instances in which the preview effect does not occur. Therefore, the number of distractor items and the presence of motion (or gap and no-gap) should interact. Likewise, the search items should affect RT equivalently in both display conditions, meaning that the number of search items and display type should not interact.

As can be seen in the left-hand panel of Figure 4, the number of distractor items had a smaller effect on RT during the movement condition relative to the static condition, as demonstrated by the interaction between the number of distractor items and the type of display $[F(2,22)=$ $4.7, p<.05]$. The number of search items and the type of display failed to interact $(F<1)$, meaning, as can be seen in the right-hand panel of Figure 4, that the number of search items affected RTs equivalently in both conditions.

\section{Discussion}

Observers in Experiment 2 demonstrated a preview effect when the stimuli were defined by motion. In this case, the motion did not occur while the search stimuli were present, but occurred $750 \mathrm{msec}$ before the presentation of the stimuli. This is in contrast to the live fly experiments of Verghese and Pelli (1992) and Royden et al. (2001), in which the task was to locate the single moving dot (the "live fly") among a set of static dots ("dead flies"), and search was unaffected by the number of distractor items in the display.

Although Experiment 2 demonstrated that motion could lead to a preview effect, the question remains regarding the role that motion played. One possibility is that participants were selectively attending to the briefly moving stimuli and ignoring the distractors. Another possibility is that the transients allowed participants to segregate the display into static and briefly moving stimuli and search either set at will by assigning which would serve as figure and which would serve as ground. The finding of Donk and Theeuwes (2001) that a preview effect was not possible when the distractor items were onsets and the search items were defined by an equiluminant color change suggests that the preview effect is not a case of simple segregation but rather the act of actively attending to transient stimuli.

\section{Experiment 3: Marking or Motion Segregation}

Experiment 3 was designed to test the segregation hypothesis and was identical to Experiment 2 except that the target was located among the static items (i.e., the search items were static and the distractor items were defined by a brief movement). A finding that participants were able to successfully mark in Experiment 3 would suggest that participants were segregating the display into static and dynamic elements and able to assign at will which group would serve as figure and which group would serve as ground. On the other hand, a finding that participants were unable to mark in Experiment 3 would suggest that the results of Experiment 2 were due to observers actively attending to transients rather than simple segregation.

\section{Method}

Participants. Eight students (4 males and 4 females) from the University of Illinois were paid to serve in the study. The average age of the participants was 23.9 years.

Procedure. The procedure and stimuli were identical to those of Experiment 2 except that the target was located among the static rather than the dynamic items. Participants were instructed to attend to the static items and to ignore the briefly moving stimuli.

\section{Results}

Error rates. Error rates were analyzed using a threeway repeated measures ANOVA with trial type (static or movement), the number of distractor items $(3,6$, or 9$)$, and the number of search items $(3,6$, or 9$)$ as independent variables. None of the main effects or interactions reached significance. The overall error rate was $2.8 \%$.

Response times. RTs for the static and movement conditions relative to the number of distractor and search items can be seen in Figure 5. RTs were analyzed using a three-way repeated measures ANOVA, with trial type (static or movement), the number of distractor items $(3,6$, or 9 ), and the number of search items $(3,6$, or 9) as independent variables. As in Experiment 2, RTs were a function of the number of distractor or number of search items in the display $[F(1,14)=47.0$ and 26.6, $p$ s $<.05$, for the number of search and distractor items, respectively]. However, trial type had no effect on RTs.

Critically, trial type and the number of distractor items failed to interact $[F(2,14)<1]$. As can be seen in the lefthand panel of Figure 5, participants were treating the distractor items identically in each condition, and therefore were unable to mark. Interestingly, trial type and the number of search items interacted $[F(2,4)=12.4, p<.01]$, with the number of search items in the movement condition having a larger effect than the number of search items in the static items. Although the interference in the movement condition might suggest that motion captured attention, if the moving items captured attention and were searched first, we would still expect the slopes for the number of search items to be identical in the static and motion conditions. None of the other interactions reached significance.

\section{Discussion}

In Experiment 3, participants were unable to mark when the search items were defined as the static items on the screen. This indicates that participants were not able to segregate the displays on the basis of motion and search either group at will. This is in contrast with previous research showing that search for a single static element (the 


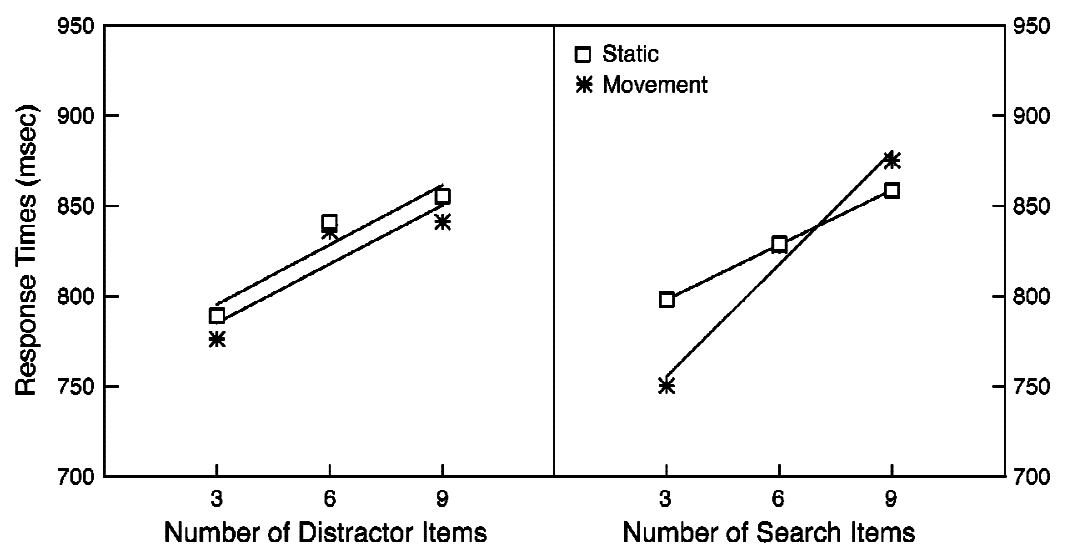

Figure 5. Response times for Experiment 3. As can be seen in the left-hand panel, the distractor items had an equivalent effect in the static and movement conditions, indicating that participants were unable to visually mark when the search stimuli were defined as the static items. As shown in the right-hand panel, responses as function of the number of search items slowed more for the movement than for the static conditions, suggesting that the irrelevant moving items might have captured attention.

"dead fly") among moving elements ("live flies"), although not as efficient as searching for the single moving element among static elements, is still quite efficient when the dynamic elements move in synchrony $(4.2 \mathrm{msec} /$ item, Royden et al., 2001). The critical difference is that in Experiment 3, observers need to hold the locations of the static items in memory for $750 \mathrm{msec}$ before the stimuli appeared, whereas in Royden et al., motion was present throughout the search process. This leads us to suspect that the preview effect is simply the act of attending to groups of stimuli defined by transients. In addition, the number of search items and the presence of motion interacted; this suggests perhaps that the moving items, although not the target of the search, might have captured attention.

\section{Summary of Experiments 1-3}

Experiments 1-3 were designed to test whether the preview effect could occur for transient stimuli other than onsets. Experiment 1 demonstrated that a preview effect could occur for offsets, and Experiment 2 demonstrated that a preview benefit could occur for motion. In addition, Experiment 1 replicated the finding of Donk and Theeuwes (2001) that a preview effect does not occur for equiluminant color transients, and Experiment 3 demonstrated that the preview effect does not occur for static items that are not defined by a unique transient. This suggests that the preview effect occurs only for items that uniquely stimulate the magnocellular system.

Experiment 2, relative to previous preview search experiments, was unique not only because it used motion to define the search items, but also because every item in the visual field underwent a transient change (the offset of the placeholders) after the defining transient (motion) occurred. If the preview effect is simply the involuntary capture of attention by transient stimuli, then the offset of the placeholders should have captured attention and abolished the benefit for the search items. This lack of attentional capture by offsets in Experiment 2 suggests that the preview effect is modulated by top-down attentional control settings, as in the contingent attentional capture hypothesis of Folk and his colleagues (Folk et al., 1992, 1993; Folk et al., 1994).

\section{CONTINGENT VISUAL MARKING}

Previous research by Watson and Humphreys (Watson, 2001; Watson \& Humphreys, 1997, 1998) suggests that only certain types of transients can interfere with preview search when the target set is defined by an onset. For example, when other onsets or offsets occur at the same time as the marking onset, the preview benefit does not occur (Watson \& Humphreys, 1997). On the other hand, onsetdefined preview search does occur in the presence of motion, or at least when motion has been present before the appearance of the marking items (Watson, 2001, Experiment 1). Likewise, when the search set is defined by motion, a subsequent offset (Experiment 2) does not interfere with preview search. This suggests that luminance changes, in the form of onsets and offsets, belong to the same class of transient, whereas motion defines a distinct transient class, at least with regard to preview search.

In this section we investigate the contingent marking hypothesis, which states that the preview benefit is dependent on a top-down attentional set for a specific class of transients. Accordingly, irrelevant transients that match the current attentional set should interfere with preview search, whereas transients that do not match the current attentional set should not interfere. To test this hypothesis, in the following series of experiments, as in Experiments 2 and 3, every item in the display underwent an irrelevant change after the presentation of the marking transient but 
before the search stimuli were revealed. Therefore, according to the contingent marking hypothesis, when the irrelevant transient matches the current attentional set, attention should be drawn to every item in the display and no preview benefit will occur (i.e., the number of distractor items should affect search times equivalently in the nogap and gap conditions). Preliminary evidence for this hypothesis was found in Experiment 2, in which the presence of offsets had no effect on preview search when the attentional set was for motion.

\section{Experiment 4: Marking by Onsets in the Presence of Motion}

In Experiment 4 we investigated whether motion would interfere with preview search when participants have an attentional set for onsets. Recently, Watson (2001) found that motion did not interfere with preview search when the onsets joined a group of distractor items already present on a rotating plane. In Watson's case, the motion was present in the display before the onsets occurred, and it remains to be seen whether the introduction of new motion in Experiment 4 will interrupt preview search or not. In contrast, Watson and Humphreys (1998) found that the preview benefit was abolished when a group of moving old items suddenly stopped moving when the new items onset. Although this might suggest that motion can interfere when the search items are defined by an onset, another possibility is that the sudden stopping of the moving distractors led to a change in velocity, which in turn produced a local change in luminance.

To test whether irrelevant motion interferes with preview search, we introduced irrelevant motion after the marking onset but before the stimuli were revealed. To prevent participants from examining the search stimuli before the introduction of the irrelevant motion, we onset placeholders rather than the search stimuli themselves. That is, placeholders marking the locations of the old distractors onset first, followed a short time later by the onset of the placeholders for the new search stimuli. After a brief pause, all of the placeholders swirled in synchrony. After the irrelevant motion had occurred, the stimuli were painted in a green equiluminant with the gray placeholder, much as in Experiment 1B.

According to the contingent marking hypothesis, motion should have no effect on marking. In contrast, if the irrelevant motion captures attention, then every item in the display will be weighted equally and no preview benefit will occur (i.e., the number of distractor items will have an equivalent effect on RTs in the no-gap and gap conditions).

\section{Method}

Participants. Eight students (6 males and 2 females) from the University of Illinois were paid to serve in the study. The average age of the participants was 22.5 years.

Stimuli and Procedure. Except for the temporal order of events, the stimuli were identical to those used in Experiment 1B. In the gap condition, the distractor placeholders onset, followed $750 \mathrm{msec}$ later by the search placeholders (Figure 6). Approximately $300 \mathrm{msec}$ after the onset of the search placeholders, the entire display swirled in synchrony for $135 \mathrm{msec}$, followed by $315 \mathrm{msec}$ of static placeholders. After the placeholder display had ended, equiluminant search and distractor stimuli were drawn on their respective placeholders. In the no-gap condition, the distractor and search placeholders appeared all at once. Participants were told to attend to the second group of placeholders that onset and to ignore the first group.

\section{Results}

Error rates. Error rates were analyzed using a threeway repeated measures ANOVA with trial type (gap or nogap), the number of distractor items $(3,6$, or 9), and the number of search items $(3,6$, or 9$)$ as independent variables. None of the main effects or interactions reached significance. The overall error rate was $2.1 \%$.

Response Times. RTs for the gap and no-gap conditions relative to the number of distractor and search items can be seen in Figure 7. RTs were analyzed using a threeway repeated measures ANOVA, with trial type (gap or no-gap), the number of distractor items $(3,6$, or 9$)$, and the number of search items $(3,6$, or 9$)$ as independent variables. Both the number of search items and the number of distractor items affected RTs $[F(2,14)=85.4$ and 62.2 , $p \mathrm{~s}<.01$, for the number of search and distractoritems, re-

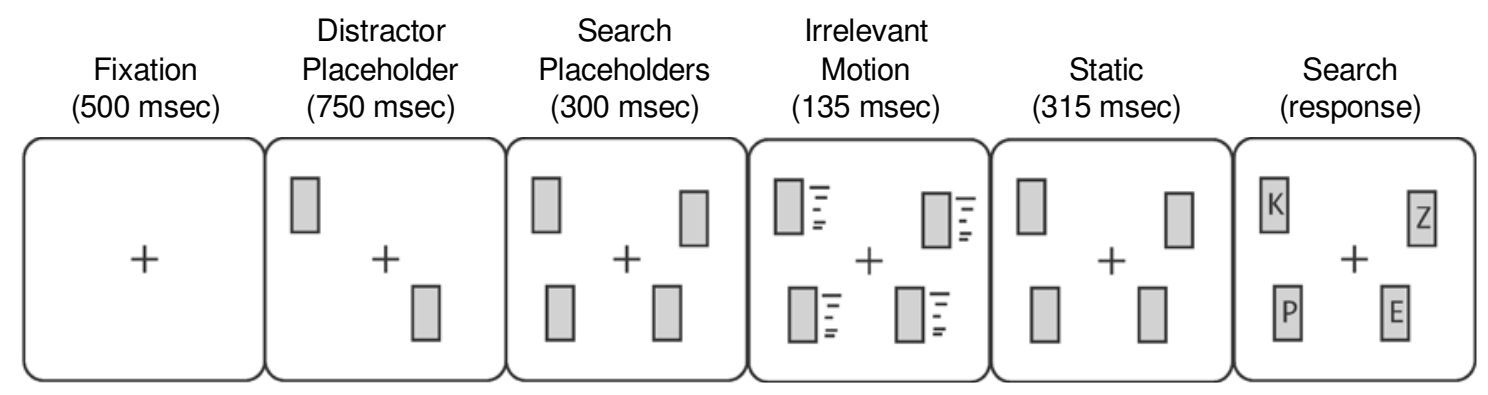

Figure 6. Time course and stimuli for the gap condition of Experiment 4. Participants initially viewed a fixation cross, which was replaced $500 \mathrm{msec}$ later by the first (old) set of placeholders. After $750 \mathrm{msec}$, the second (new) set of placeholders joined the first set by onsetting. An irrelevant motion lasting $135 \mathrm{msec}$ was introduced $300 \mathrm{msec}$ later by swirling all of the premasks in the display in a counterclockwise direction. After a 315-msec delay, the stimuli were revealed by being painted in a green that was equiluminant with the gray premasks. In the no-gap condition, the search and distractor placeholders onset all at once. 


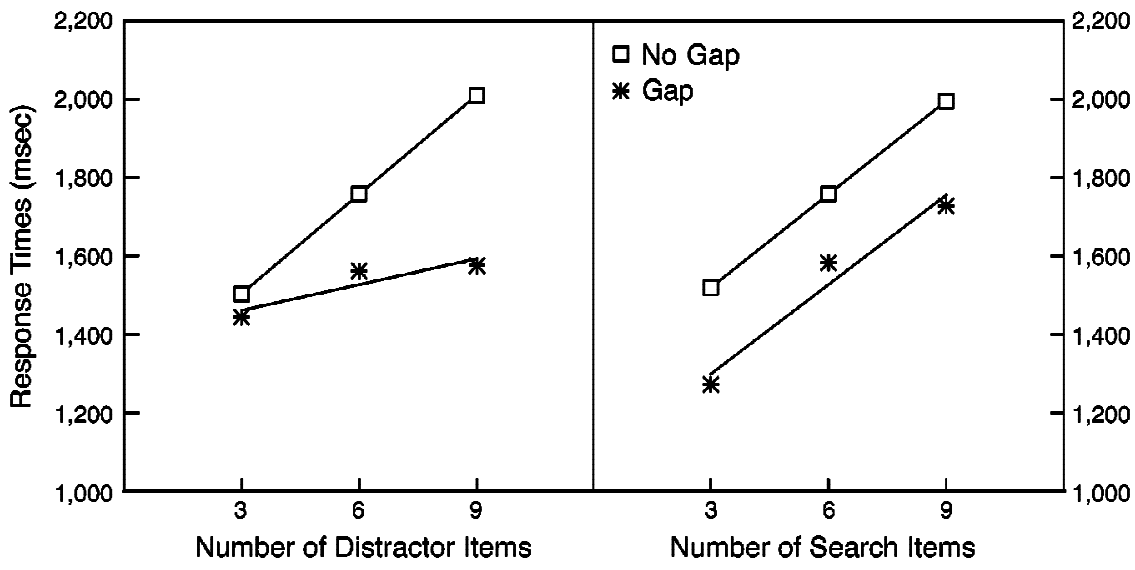

Figure 7. Response times for Experiment 4, in which the onset of the stimuli was followed by whole-display motion. As can be seen in the left-hand panel, the distractor items had a smaller effect in the gap relative to the no-gap condition, indicating that participants were able to visually mark. As shown in the right-hand panel, search items had an equivalent effect in both conditions.

spectively]. Trial type and the number of distractor items interacted $[F(2,14)=4.6, p<.05]$, suggesting that participants were able to successfully visually mark. None of the other interactions reached significance.

\section{Discussion}

Experiment 4 demonstrated that motion does not interfere with preview search when observers have an attentional set for onsets. This supports our hypothesis that the introduction of a new transient will interfere with preview search only if the new transient is from the same class as the transient used to define the search objects (see the Discussion section of Experiment 5 for the definition of transient class). Had the introduction of motion been able to capture attention, both the distractor items and the search items would have been attended equivalently, and there would have been no performance difference between the gap and no-gap conditions. Similar evidence for the independence of motion and onsets comes from Watson (2001), who found that a preview benefit could occur when onsets joined a group of items already present on a rotating plane. However, in Watson's experiment, the motion was apparent before the introduction of the onsets, and might have allowed observers to treat the rotating objects as a coherent group undergoing transformation. Indeed, when the search and the distractor items underwent incoherent motion transformations, the preview effect was abolished (Watson, 2001, Experiment 2).

Interestingly, Olivers, Watson, and Humphreys (1999) found no preview benefit when the new search items were added to a field of moving distractors. One possibility is that the disappearance and reappearance of items as they scrolled on and off the screen captured attention, and this in turn overrode any potential preview benefit. Indeed, the results of Watson (2001) suggest that the disappearance and reappearance of items along the edge of the screen was responsible for the lack of preview benefit observed by Olivers et al. (1999), rather than motion per se.

\section{Experiment 5: Marking by Onsets in the Presence of Offsets}

In Experiment 4, we found that the introduction of motion did not abolish the preview effect, which is consistent with the prediction of our contingent marking hypothesis. In Experiments 5 and 6, we introduced transients to the display from the same class as the transient marking the location of the search stimuli. According to our contingent marking hypothesis, these superfluous transients should interfere with the preview effect by guiding attention from the search items to all of the items in the display.

Experiment 5 featured a paradigm similar to that of Experiment 4 , in which the onset of placeholders marked the locations of the search and distractor objects. After the search items had been presented, all of the placeholders offset, revealing the search display. Given that offsets belong to the same transient class as onsets, we predicted that the placeholder offsets should interfere with preview search. More specifically, if the offset of the placeholders interferes with marking defined by onsets, then performance should be equivalent in the gap and no-gap conditions, and no preview benefit should occur.

\section{Method}

Participants. Eight students (3 males and 5 females) from the University of Illinois were paid to serve in the study. The average age of the participants was 23.4 years.

Stimuli. The stimuli were identical to those used in Experiments 2 and 3 .

Procedure. The procedure was similar to the one used in Experiment 4, except that the premasks offset to reveal the stimuli and there was no motion. The timecourse and displays are illustrated in Figure 8 . The placeholders were removed (offset) $1,000 \mathrm{msec}$ after the final placeholders had appeared. Participants were instructed 


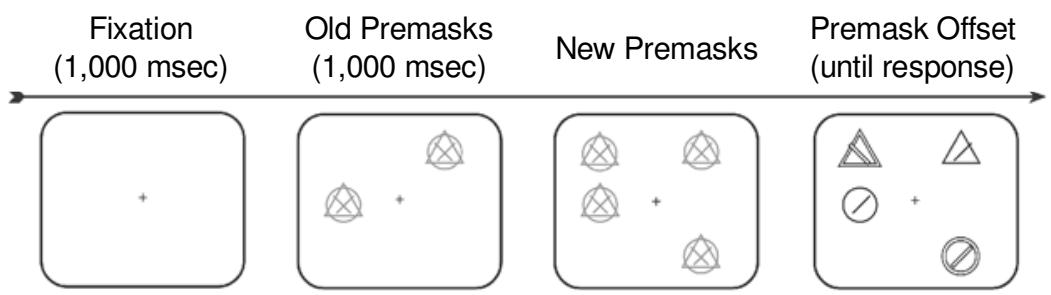

Figure 8. Example of the displays used in Experiment 5. Each trial began with a display that was empty except for a fixation cross. One second later, the placeholders for the distractor items onset. After $1 \mathrm{sec}$, they were joined by the placeholders (gray outline) for the search items (hollow outline). The placeholders offset $1 \mathrm{sec}$ later, revealing the search items. In the example, only two distractor and two search items are present; in the actual experiment, the number of distractor and search items ranged from three to nine items.

that the target would appear in the second group of onsets and that they should ignore the first group.

\section{Results}

Error rates. Error rates were analyzed using a threeway repeated measures ANOVA with trial type (gap or nogap), the number of distractor items $(3,6$, or 9), and the number of search items $(3,6$, or 9$)$ as independent variables. None of the main effects or interactions reached significance. The overall error rate was $2.1 \%$.

Response times. RTs for the gap and no-gap conditions relative to the number of distractor and search items can be seen in Figure 9. RTs were analyzed using a three-way repeated measures ANOVA, with trial type (gap or no-gap), the number of distractor items $(3,6$, or 9$)$, and the number of search items $(3,6$, or 9) as independent variables. Both the number of search items and the number of distractor items affected RTs $[F(2,14)=42.3$ and $17.7, p$ s $<.05$, for the number of search and distractor items, respectively], but trial type had no effect. None of the interactions reached significance $\left(F_{\mathrm{s}}<1\right)$.

\section{Discussion}

Experiment 5 demonstrated that when offsets occurred subsequent to the marking onset, the preview effect was abolished. This suggests that when observers have an attentional set for onsets, a subsequent transient of the same class (luminance change) will abolish the preview effect.

What is not clear at this point is the definition of transient class. Given the similarities between our contingent marking hypothesis and contingent capture, a reasonable place to start would be with the contingent capture literature of Folk and his colleagues (Folk et al., 1992, 1993). They found that when there is an attentional set for a specific type of singleton (e.g., color, but see Bacon \& Egeth, 1994), other types of singletons do not capture attention (e.g., onsets). Originally Folk and his colleagues(1994) suggested that contingent capture might be due to differential weighting of static and dynamic pathways. However, later research demonstrated contingent capture for specific colors (Folk \& Remington, 1998). In addition, Atchley, Kramer, and Hillstrom (2000) have demonstrated that contingent capture can be specific to onsets or offsets.

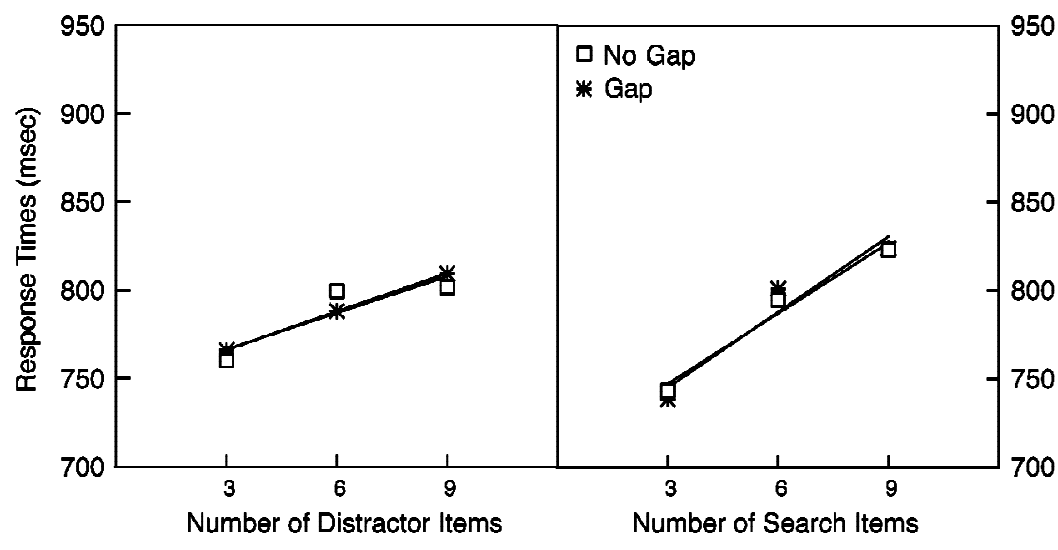

Figure 9. Response times for Experiment 5, in which the onset of the stimuli was followed by a whole-screen offset of the placeholders. As can be seen in the left-hand panel, the distractor items had an equivalent effect in the gap and no-gap conditions, indicating that participants were unable to visually mark when the onset of the premasks defining items to search were followed by offsets. As shown in the right-hand panel, search items had an equivalent effect in both conditions. 
Table 1

Experiments in Which Subsequent or Simultaneous Transients Did or Did Not Abolish Marking (When the Marking Transient Was Followed by a Transient of the Same Class, Marking Was Abolished)

\begin{tabular}{llccc}
\hline \multicolumn{1}{c}{ Experiment } & Marking Transient & Simultaneous Transient & Subsequent Transient & Marking? \\
\hline 1 & Onset/Offset & - & - & Yes \\
2 & Motion & - & Offset & Yes \\
4 & Onset & - & Motion & Yes \\
5 & Onset & - & Offset & No \\
6 & Motion & - & Motion & No \\
Atchley \& Jones (2000) & Onset & - & Onset & No \\
W. \& H. (1997), Exp. 4 & Onset & Onset & - & No \\
W. \& H. (1997), Exp. 5 & Onset & Offset & - & No \\
W. \& H. (1997) Exp. 1 & Unique color + Onset & Unique color + Onset & & No \\
\hline
\end{tabular}

Note-W \& H, Watson and Humphreys.

This clearly shows that several of the features that can be specified for contingent capture do not lead to a preview benefit (Table 1). For example, contingent capture can occur for specific colors, but the same does not hold true for the preview effect, as demonstrated by the lack of a benefit in numerous no-gap conditions in which the old and new items occurred in different colors (Watson \& Humphreys, 1997, Experiment 1; Experiments 2,3, 5, and 6 of this paper). Likewise, Atchley et al. (2000) have demonstrated that when there is an attentional set for onsets, offsets do not capture attention, and vice versa. However, as demonstrated in Experiment 5, when the target set is defined by onsets, subsequent offsets will interfere with preview search (see also Watson \& Humphreys, 1997, Experiments 4 and 5).

In Experiment 5, we demonstrated that offsets could interfere with onset-defined preview search, suggesting that onsets and offsets belong to the same class of visual transient with regard to preview search. In Experiment 6, we investigated another case of potential intraclass interference: whether irrelevant motion will interfere with motiondefined preview search.

\section{Experiment 6: Marking by Motion Interrupted by Subsequent Motion}

As predicted by the contingent marking hypothesis, observers in Experiment 5 were unable to mark when the marking onset was followed by a subsequent offset. In Experiment 6 we predicted that subsequent motion transients would interfere with preview search defined by motion.

Experiment 6 was identical to Experiment 2 except that prior to the placeholders revealing the stimuli, the entire display moved synchronously. In the marking-motion condition, participants were instructed to pay attention to the moving subset of stimuli and to ignore the subsequent motion.

\section{Method}

Participants. Eight students ( 3 males and 5 females) from the University of Illinois were paid to serve in the study. The average age of the participants was 22.7 years.

Procedure. The procedure was similar to that used in Experiment 2, and the timecourse of events can be seen in Figure 10. Participants first viewed a set of placeholders marking the location where the stimuli would subsequently occur. After $750 \mathrm{msec}$, in the motion condition, a subset of the placeholders synchronously moved in a swirling motion for $135 \mathrm{msec}$; in the static condition, the placeholders remained static. The placeholders then remained static for another $750 \mathrm{msec}$. In both the static and motion conditions, the entire display then moved in synchrony for $135 \mathrm{msec}$. The placeholders were removed $240 \mathrm{msec}$ later, revealing the search stimuli. Participants were told to attend to the items that briefly moved and to ignore the static items or any subsequent motion.

\section{Results}

Error rates. Error rates were analyzed using a threeway repeated measures ANOVA with trial type (markingmotion or static), the number of distractor items $(3,6$, or 9$)$, and the number of search items $(3,6$, or 9$)$ as independent variables. None of the main effects or interactions reached significance. The overall error rate was $2.3 \%$.

Response times. RTs for the marking-motion and static conditions relative to the number of distractor and search items can be seen in Figure 11. RTs were analyzed using a three-way repeated measures ANOVA, with trial type (marking-motion or static), the number of distractor items $(3,6$, or 9$)$, and the number of search items $(3,6$, or 9$)$ as independent variables. Both the number of search items and the number of distractor items affected RTs $[F(2,14)=$ 28.9 and $9.0, p \mathrm{~s}<.05$, for the number of search and distractor items, respectively], but trial type had no effect. As in Experiment 5, none of the interactions reached significance $\left(F_{\mathrm{S}}<1\right.$ for the two interactions featuring trial type and the number of distractor or search items).

\section{Discussion}

Like Experiment 5, Experiment 6 demonstrated that when a transient was followed by a transient of the same class, the preview effect was abolished. Experiment 6 extended these findings to instances in which motion was the marking transient.

\section{Summary of Experiments 4-6}

According to our contingent marking hypothesis, transients that occur subsequent to (but prior to the presentation of the search stimuli) or simultaneous with the marking transient will interfere with preview search if they are from the same transient class. Prior research by Watson 


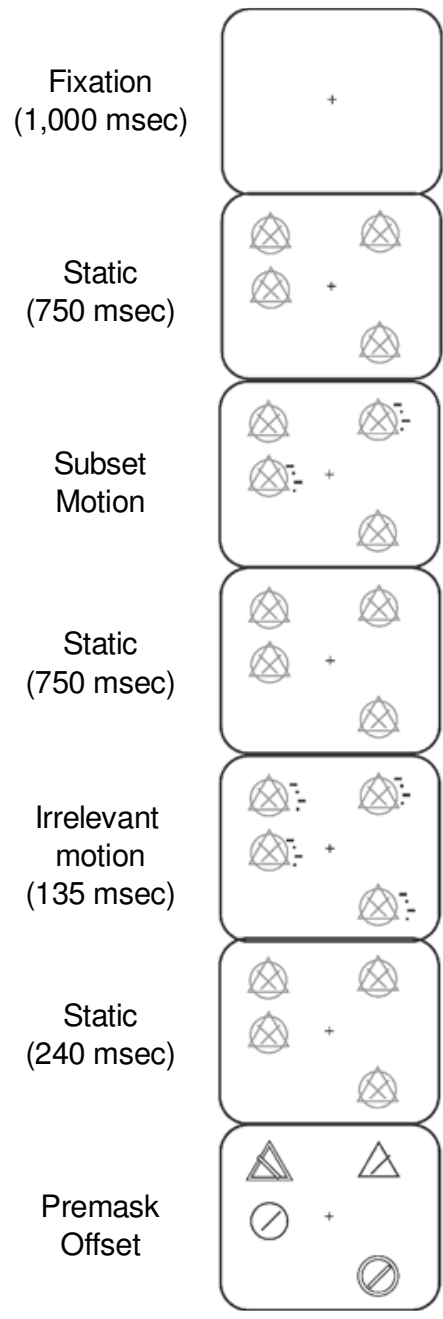

Figure 10. Time course and stimuli for the motion condition of Experiment 6. The stimuli and time course were identical to those used in Experiment 2, except that an irrelevant motion was added to the display $750 \mathrm{msec}$ after the subset motion. In the static condition, the subset of premasks marking the location of the search stimuli remained static.

(2001) and Watson and Humphreys $(1997,1998)$ suggested that because offsets interfered with onset-defined preview search, these types of luminance changes were treated as the same class of transient for preview search. Motion, on the other hand, did not interfere with onsetdefined preview search, suggesting that motion belonged to a separate transient class. In Experiments 2 and 4, observers were successfully able to search the search stimuli when they were defined by motion or onset transients and followed by offsets or motion transients, respectively. In contrast, in Experiments 5 and 6, when the marking transient was an onset and was followed by offsets, or when the marking transient was motion and was followed motion transients, the preview effect was not evident.

The results of these experiments, as well as the results of Experiments 4 and 5 from Watson and Humphreys
(1997), suggest that preview search is subjected to topdown constraints.

\section{GENERAL DISCUSSION}

We had two goals for the experiments in this paper. The first goal was to determine whether magnocellular transients other than onsets could lead to a preview effect. In Experiment 1 we demonstrated that luminance onset and offset transients can lead to a preview benefit, but color transients do not (see also Donk \& Theeuwes, 2001). In Experiment 2 we extended the preview search phenomena to motion transients. Our second goal was to determine whether preview search was constrained by a top-down attentional set for specific classes of transients. If preview search is indiscriminate in regard to which transients lead to a preview effect, then any secondary magnocellular transient would interfere with preview search. In Experiments $2,4,5$, and 6 , we demonstrated that secondary transients interfered with preview search only when they were from the same class of transient as the marking transient. This suggests that preview search is subjected to top-down attentional constraints.

\section{Inhibition of Distractor Items or Attention to Search Items?}

Previously, Watson and Humphreys $(1997,1999)$ suggested that the preview search phenomenon occurs through the active inhibition of the distractor items in the display. To more directly test the inhibition account, Watson and Humphreys (1999) employed the probe-dot technique (Klein, 1988). In their experiment, on a small subset of trials $(24 \%)$, participants were signaled via a tone that occurred simultaneously with the search stimuli to determine whether or not a probe was present somewhere in the display rather than perform the normal search task. In the gap and no-gap trials, the probe was detected equally as well when it occurred in one of the search items. However, in the gap condition, the probe was less likely to be detected when it occurred among the distractor items. This suggested to Watson and Humphreys that the probe was less likely to be detected because inhibition had built up at the location of the distractor items during the gap period.

Another explanation for the probe effect is that participants' attention might simply have been drawn to the last transient to occur in the display. This makes sense because in both the gap and the no-gap conditions, the final onset in each condition contained the search set. Therefore, the weakened detection performance for probes that occurred on distractor items during the gap condition might have been because the onset drew attention to the search items and away from the distractor items rather than because of the active buildup of inhibition during the gap period. At this point, the active attending account is indistinguishable from the active inhibition account of Watson and Humphreys (1997, 1999).

However, according to the active inhibition hypothesis, the gap period is needed in order for inhibition to build up 


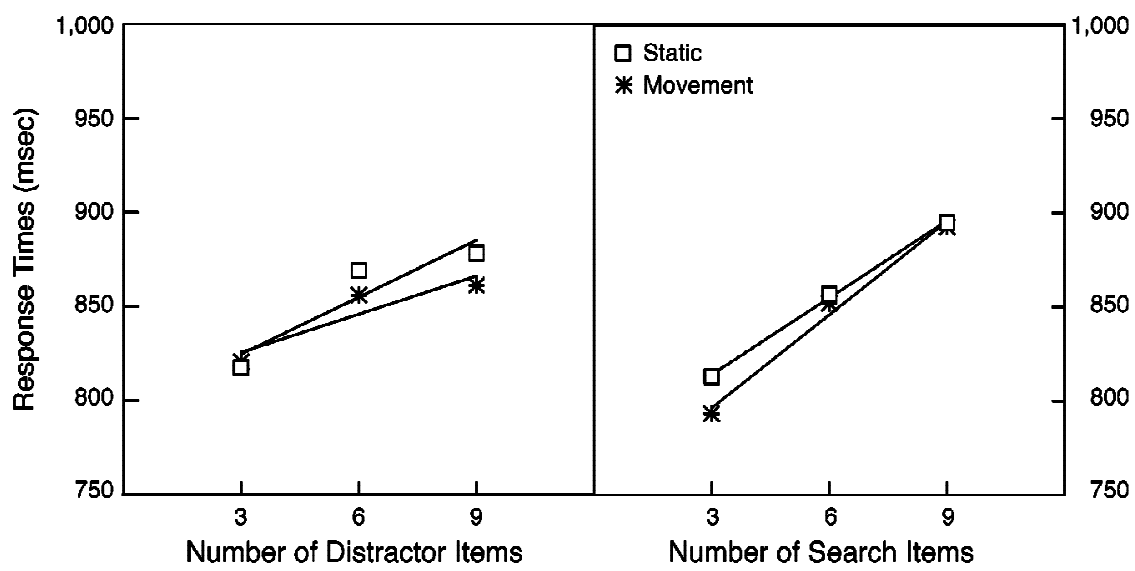

Figure 11. Response times for Experiment 6, in which the search items were defined by motion and were followed later by whole-screen motion. As can be seen in the left-hand panel, the distractor items had an equivalent effect in the gap and no-gap conditions, indicating that participants were unable to visually mark when the motion-defined search stimuli were followed by whole-screen motion. As shown in the right-hand panel, search items had an equivalent effect in both conditions.

at the distractor items. If the gap period is too short (around $400 \mathrm{msec}$; Watson \& Humphreys, 1997), inhibition does not have sufficient time to build up and the preview effect does not occur or is reduced. However, the results of our Experiment 3 and Donk and Theeuwes's Experiment 2 (2001) indicate that the preview effect occurs only when the search items are defined by a luminance or motion transient - if only the distractor items are defined by a transient, then no preview effect occurs. Not only does this suggest that the processes responsible for preview search do not begin until and unless the search items undergo a magnocellular transient, but it also suggests that the processes responsible for the preview benefit perform no function during the gap period. The importance of the gap period in this instance might simply serve to minimize one transient from masking another transient of the same class. For example, Kramer, Cassavaugh, Irwin, and Peterson (2001) found that a secondary onset failed to capture attention when it occurred within $250 \mathrm{msec}$ of an earlier onset.

More recently, we (Belopolsky, Peterson, \& Kramer, 2002a, 2002b) have looked at attentional effects during preview search using behavioral and electrophysiological measures. Unlike Watson and Humphreys (1999), we placed the probe stimuli during the gap period. In the electrophysiologicalexperiment, the probe was completely irrelevant to the task at hand and was always present, whereas in the behavioral experiments, participants had to make a speeded response to the probe when it occurred on a subset of trials. The probe was an isoluminant color change to the old distractor items that occurred during the gap period and had no detrimental effect on the preview benefit.

To test the attentional effects of preview search, a preview search condition was contrasted to a neutral and a memory condition. In the neutral condition, the task was to determine whether the fixation cross blinked once or twice, and presumably required attention to be focused on the fixation cross and drawn away from the distractor items. In the memory condition, participants were quizzed about the identities of the old distractor items that had occurred during the gap period. The encoding process presumably required participants to actively attend to the old distractor items. Event-related potentials (ERPs) timelocked to the probe showed increased and statistically identical P1 and N1 components in the search and memory conditions relative to the neutral condition. Likewise, in the behavioral experiment, RTs to the probe were identical and faster in the memory and search conditions relative to the neutral condition. According to the inhibitory visual marking account, ERPs should have been diminished and RTs slowed in the search condition relative to the neutral and memory conditions. These results suggest that the old distractor items are actively attended rather than inhibited during the gap period.

Although the importance of the final transient in allowing preview search in the present studies and the positive attentional effects during the gap period in our behavioral and ERP studies (Belopolsky et al., 2002a, 2002b) suggest that no meaningful processing occurs during the gap period, Olivers and Humphreys (2002) found a carryover from one search display to another where RTs to a target are slowed if it shares the color with the old distractor items that occurred earlier in the trial. Although at first glance these results would appear to support the inhibition visual marking account, a more likely possibility is that Olivers and Humphreys observed negative priming (Tipper, 1985).

\section{Preview Search Is Not Simple Segregation}

One possibility is that the preview effect is simply due to Gestalt grouping, perhaps through the mechanism of common fate. Although common fate has traditionally 
been described as the grouping of objects that move together, recently common fate has been demonstrated for items that share a luminance change (Sekuler \& Bennett, 2001). This would predict that participants can segregate the display and actively assign which group will serve as the figure and which will serve as ground. However, in our Experiment 3 and Experiment 2 of Donk and Theeuwes (2001), we find no evidence for this-if participants were able to segregate the display into transient and static items and search only the static items, then the transient items would have had no effect on search times and the preview effect would have occurred. As it stands, the preview effect occurs only when the search items undergo a magnocellular transient, indicating that visual marking is not simply a case of Gestalt grouping and segregation.

\section{Contingent Marking Is Not Contingent Capture}

Similar to our contingent marking hypothesis is the contingent capture hypothesis of Folk and his colleagues (Folk et al. 1992, 1993; Folk et al., 1994). According to the contingent capture hypothesis, an item will capture attention only if its features match the top-down attentional set. For example, when participants are looking for a color singleton, a sudden onset will not capture attention, and vice versa. At first glance, our contingent marking hypothesis might appear to be an instance of the contingent-capture hypothesis, but applied to more than one search item. However, one area where contingent capture and contingent marking differ is in the area of color. In the singleton detection tasks of Folk and his colleagues, color singletons captured attention when they matched the attentional set. However, in our no-gap conditions and the original experiments of Watson and Humphreys (1997), the preview effect did not occur when the search items were defined solely by a unique color. Second, Atchley et al. (2000) have demonstrated that onsets do not capture attention when there is an attentional set for offsets, and vice versa. In contrast, we (Experiment 5) and Watson and Humphreys (1997, Experiments 4 and 5, ) find that onsets and offsets interfere with each other during preview search (Table 1). Taken as whole, these findings suggest that the transient signals used for preview search are tapped at a level that is different from those used by contingent capture.

\section{Conclusions}

In contrast to the active inhibition account of Watson and Humphreys (1997), the preview effect critically depends on the search stimuli being defined by a magnocellular transient. This suggests that the preview effect does not occur through the active inhibition of distractor items during the gap period, but rather is triggered by transients detectable by the magnocellular system. In addition, the types of transients that lead to preview search are partially determined by attentional control settings - when the target transient is an onset, motion will not interfere with preview search, and when the target transient is motion, an onset will not interfere with preview search.
Preview search is not a case of simple figure-ground segmentation, but instead might be the active grouping of objects marked by a common transient. That is, when attention is drawn to the new items, attention appears to be drawn to the singular group rather than to the individual items. For example, results from Watson (2001, Experiment 2) show that when the search items join a group of distractor items traveling along heliocentric rings spinning in opposite directions, the preview effect does not occur. This suggests that the preview effect will not occur when the search items cannot be contained as a coherent group. However, what is not clear from that experiment is whether or not the lack of a preview effect is due to the shear forces destroying local relationships among the distractor or among the search items. Grouping by a common transient, much like common fate, would suggest that preview search can occur only when the local spatial relationships among the search items are preserved. Alternatively, the constantly changing spatial relationships might have (Gibson, Li, Skow, Brown, \& Cooke, 2000; Horowitz \& Wolfe, 1998; Kristjansson, 2000; Peterson, Kramer, Wang, Irwin, \& McCarley, 2001) made it impossible to keep track of which items had and had not been examined, making preview search impossible.

\section{REFERENCES}

Atchley, P., \& Jones, S. (2000, November). To mark or not to mark: Automaticity of visual marking. Abstracts of the Psychonomic Society, 5, 93-94.

Atchley, P., Kramer, A. F., \& Hillstrom, A. (2000). Contingent capture for non-onsets: Attentional set for perceptual transients. Journal of Experimental Psychology: Human Perception \& Performance, 26, 594-606.

Bacon, W. F., \& Egeth, H. E. (1994). Overriding stimulus-driven attentional capture. Perception \& Psychophysics, 55, 485-496.

Belopolsky, A. V., Peterson, M. S., \& Kramer, A. F. (2002a). Attentional mechanisms of visual marking: An event-related potential study. Paper presented at the annual workshop on object perception and memory, Kansas City, KS.

Belopolsky, A. V., Peterson, M. S., \& Kramer, A. F. (2002b). Electrophysiological analysis of visual marking: Evidence against the inhibition hypothesis. Manuscript submitted for publication.

Donk, M., \& Theeuwes, J. (2001). Visual marking beside the mark: Prioritizing selection by abrupt onsets. Perception \& Psychophysics, 63, 891-900

Folk, C. L., \& Remington, R. W. (1998). Selectivity in distraction by irrelevant featural singletons: Evidence for two forms of attentional capture. Journal of Experimental Psychology: Human Perception \& Performance, 24, 847-858.

Folk, C. L, Remington, R. W., \& Johnston, J. C. (1992). Involuntary covert orienting is contingent on attentional control settings. Journal of Experiment Psychology: Human Perception \& Performance, 18, 1030-1044.

Folk, C. L., Remington, R. W., \& Johnston, J. C. (1993). Contingent attentional capture: A reply to Yantis (1993). Journal of Experimental Psychology: Human Perception \& Performance, 19, 682-685.

Folk, C. L., Remington, R. W., \& Wright, J. H. (1994). The structure of attentional control: Contingent attentional capture by apparent motion, abrupt onset and color. Journal of Experimental Psychology: Human Perception \& Performance, 20, 317-329.

Gibson, B. S., Li, L., Skow, E., Brown, K., \& Cooke, L. (2000). Searching for one versus two identical targets: When visual search has a memory. Psychological Science, 11, 324-327.

Horowitz, T. S., \& WolfE, J. M. (1998). Visual search has no memory. Nature, 394, 575-577. 
ISHIHARA, S. (1989). Ishihara's tests for colorblindness: 24 plates edition. Tokyo: Kanehara.

JiAng, Y., Chun, M. M., \& Marks, L. E. (2002a). Visual marking: Dissociating effects of new and old set size. Journal of Experimental Psychology: Human Perception \& Performance, 28, 293-302.

Jiang, Y., Chun, M. M., \& MARKs, L. E. (2002b). Visual marking: Selective attention to asynchronous temporal groups. Journal of Experimental Psychology: Human Perception \& Performance, 28, 717-720.

KLEIN, R. (1988). Inhibitory tagging system facilities visual search. $\mathrm{Na}$ ture, 334, 430-431.

Kramer, A. F., Cassavaugh, N. D., Irwin, D. E., \& Peterson, M. S. (2001). Influence of single and multiple onset distractors on visual search for singleton targets. Perception \& Psychophysics, 63, 952-968.

KRISTJANSSON, A. (2000). In search of remembrance: Evidence for memory in visual search. Psychological Science, 11, 328-332.

LeHKy, S. R. (2000). Deficits in visual feature binding under isoluminant conditions. Journal of Cognitive Neuroscience, 12, 383-392.

Livingstone, M. S., \& Hubel, D. H. (1987). Psychophysical evidence for separate channels for the perception of form, color, movement, and depth. Journal of Neuroscience, 7, 3416-3468.

Livingstone, M. S., \& Hubel, D. H. (1988). Segregation of form, color, movement, and depth: Anatomy, physiology, and perception. Science, 240, 740-749.

Martin-Emerson, R., \& Kramer, A. F. (1997). Offset transients modulate attentional capture by sudden onsets. Perception \& Psychophysics, 59, 739-751.

McLeod, P., Driver, J., \& CrisP, J. (1988). Visual search for a conjunction of movement and form is parallel. Nature, 332, 154-155.

McLeod, P., Driver, J., Dienes, Z., \& Crisp, J. (1991). Filtering by movement in visual search. Journal of Experimental Psychology: Human Perception \& Performance, 17, 55-64.

Miller, J. (1989). The control of visual attention by abrupt visual onsets and offsets. Perception \& Psychophysics, 45, 567-571.

Olivers, C. N. L., \& Humphreys, G. W. (2002). When visual marking meets the attentional blink: More evidence for top-down, limitedcapacity inhibition. Journal of Experimental Psychology: Human Perception \& Performance, 28, 22-42.

Olivers, C. N. L., Watson, D. G., \& Humphreys, G. W. (1999). Visual marking of locations and feature maps: Evidence from withindimension defined conjunctions. Quarterly Journal of Experimental Psychology, 52A, 679-715.
Peterson, M. S., Kramer, A. F., Wang, R. F., Irwin, D. E., \& McCarLEY, J. S. (2001). Visual search has memory. Psychological Science, 12, 287-292.

Royden, C. S., Wolfe, J. W., \& Klempen, N. (2001). Visual search asymmetries in motion and optic flow fields. Perception \& Psychophysics, 63, 436-444.

Sekuler, A. B., \& Bennett, P. J. (2001). Common luminance changes induce grouping. Psychological Science, 6, 437-444.

Theeuwes, J., Kramer, A. F., \& Atchley, P. (1998). Visual marking of old objects. Psychonomic Bulletin \& Review, 5, 130-134.

TiPPER, S. P. (1985). The negative priming effect: Inhibitory priming by ignored objects. Quarterly Journal of Experimental Psychology, 37A, 571-590.

Verghese, P., \& Pelli, D. G. (1992). The information capacity of visual attention. Vision Research, 32, 983-995.

WATSON, D. G. (2001). Visual marking in moving displays: Feature-based inhibition is not necessary. Perception \& Psychophysics, 63, 74-84.

Watson, D. G., \& Humphreys, G. W. (1997). Visual marking: Prioritizing selection for new objects by top-down attentional inhibition of old objects. Psychological Review, 104, 90-122.

WATSON, D. G., \& HumphreYs, G. W. (1998). Visual marking of moving objects: A role for top-down feature-based inhibition in selection Journal of Experimental Psychology: Human Perception \& Performance, 24, 946-962.

Watson, D. G., \& Humphreys, G. W. (1999). Segmentation on the basis of linear and local rotational motion: Motion grouping in visual search. Journal of Experimental Psychology: Human Perception \& Performance, 25, 70-82.

\section{NOTE}

1. It could be argued that the increased difficulty (steeper search slopes and longer RTs) of searching equiluminant items, rather than the lack of a luminance change, is what led to the abolishment of visual marking in Experiment 1B. However, Experiment 4 demonstrates that visual marking is possible using the same equiluminant stimuli used in Experiment 1B, as long as the placeholders onset asynchronously.

(Manuscript received May 29, 2001; revision accepted for publication January 22, 2003.) 